\title{
High-quality draft genome sequence of a biofilm forming lignocellulolytic Aspergillus niger strain ATCC 10864
}

\author{
Sujay Paul ${ }^{1}$, Yvette Ludeña ${ }^{1}$, Gretty K. Villena ${ }^{1 *}$, Fengan $\mathrm{Yu}^{2}$, David H. Sherman² and Marcel Gutiérrez-Correa ${ }^{1 * \wedge}$
}

\begin{abstract}
Filamentous fungus Aspergillus niger has high industrial value due to their lignocellulolytic enzyme activities and ATCC 10864 is one of the few type strains of A. niger which has a unique biofilm forming capability. Here we report the first draft genome sequence of A. niger ATCC 10864 strain. The genome of A. niger ATCC 10864 is 36,172,237 bp long and comprise of 310 scaffolds with $49.5 \%$ average GC content. A total of 10,804 protein-coding genes were predicted among which 10,761 genes were with putative functions. A. niger ATCC 10864 genome coded for 709 putative carbohydrate active enzyme families distributed in six functional categories and among them glycoside hydrolases (GHs) represent the most number of families (279). Genes that include pepA, br/A, exgA, LaeA, rodA, GCN have also been identified in this study, which may play a role in biofilm formation. This high-quality draft genome sequence will facilitate our understanding of the mechanisms behind fungal biofilm formation and higher lignocellulolytic enzyme production.
\end{abstract}

Keywords: Aspergillus niger, Lignocellulolytic enzyme, Biofilm, Genomic feature

\section{Introduction}

Filamentous fungi mostly are considered as cell factories because of their ability to produce enzymes involved in the conversion of lignocellulosic compounds to simple sugars. Among these, Aspergillus niger, a GRAS microorganism, is considered a model and has been used in many industrial processes $[1,2]$. A. niger strain ATCC 10864 (CBS 122.49; IAM 2533; IAM 3009; IFO 6661; IMI 60286; JCM 22343; NBRC 6661; NRRL 330; WB 330) was previously reported to have an ability to form biofilms on polyester cloth [3-6] and interestingly, the biofilm culture of this strain can produce $50-70 \%$ more lignocellulolytic enzymes than that of conventional submerged culture $[4,7,8]$. However, due to lack of genome sequence data of this strain, the relation between biofilm formation and higher enzyme production is not well understood at the molecular level. In this context, here we illustrate a summary classification and a set of the

\footnotetext{
* Correspondence: gkvch@lamolina.edu.pe

Deceased

'Laboratorio de Micología y Biotecnología, Universidad Nacional Agraria La Molina, Av. La Molina s/n, 12 Lima, Peru

Full list of author information is available at the end of the article
}

features of $A$. niger strain ATCC 10864 with a high-quality draft genome sequence description and annotation.

\section{Organism information \\ Classification and features}

Aspergillus niger strain ATCC 10864 is a haploid, filamentous, black ornamented asexual spore (conidia) producing fungi belonging to the order Eurotiales and family Trichocomaceae (Fig. 1) and probably originated in Budapest, Hungary [9]. It is most commonly found in mesophilic environments such as decaying vegetation or soil with growth temperature from $6{ }^{\circ} \mathrm{C}-47^{\circ} \mathrm{C}$ [10] and optimal growth at $25-35{ }^{\circ} \mathrm{C}$ [11] as well as a wide $\mathrm{pH}$ range: 1.4-9.8 (Table 1). Hyphae of $A$. niger ATCC 10864 are septate, hyaline and the conidiophores are long, smooth-walled, hyaline, becoming darker at the apex and ending in a globose to subglobose vesicle [12]. Phylogenetic analysis was performed by the maximum likelihood method based on 18S rRNA gene sequences and the analysis revealed close relationship of our strain with other type strains of $A$. niger (Fig. 2). Although the genomes of three $A$. niger type strains (CBS 513.88, ATCC 1015 and $\mathrm{SH} 2$ ) have already been sequenced [13-15], biofilm 


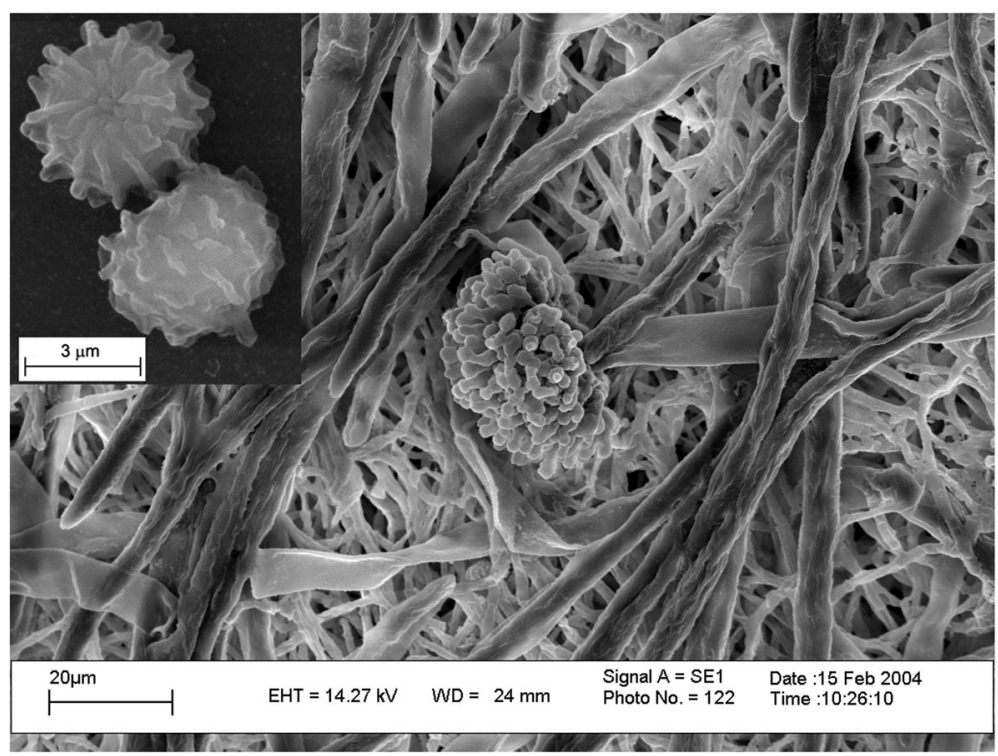

Fig. 1 Electron micrograph of Aspergillus niger strain ATCC 10864. Inset: ornamented spores

forming and high productive strain of $A$. niger such as ATCC 10864 is still being neglected and only very few sequence information are available in the databases.

\section{Genome sequencing information}

\section{Genome project history}

Experimental studies with A. niger ATCC 10864 have provided four reasons to select this strain for whole genome sequencing: 1) This is the first reported biofilm forming A. niger strain [16]. 2) Biofilm culture of this strain can produce 2-3 times more lignocellulolytic enzymes compared to conventional submerged culture $[4,7,8] .3)$ The key mechanism that controls higher levels of enzyme production of the organism in biofilm culture is still unclear. 4) The genomes of only three strains of such an industrially relevant fungus are available in the databases [13-15]. A high-quality draft genome sequence has been deposited both in Genomes On Line Database (GOLD) [17] and DDBJ/ EMBL/GenBank under accession numbers Gp0155299 and MCQH00000000 respectively. Table 2 presents the project information and its association with the minimum information about a genome sequence version 2.0 compliance [18].

\section{Growth conditions and genomic DNA preparation}

Duff (1988) [19] medium was used in this study to culture $A$ niger strain ATCC 10864. The culture medium contained per liter: $2 \mathrm{~g} \mathrm{KH}_{2} \mathrm{PO}_{4} ; 1.4 \mathrm{~g}\left(\mathrm{NH}_{4}\right)_{2} \mathrm{SO}_{4}$; 0.3 g urea; $0.3 \mathrm{~g} \mathrm{CaCl}_{2} .2 \mathrm{H}_{2} 0 ; 0.3 \mathrm{~g} \mathrm{MgSO}_{4} \cdot 7 \mathrm{H}_{2} 0 ; 1 \mathrm{~g}$ peptone; $2 \mathrm{ml}$ Tween 80; $5 \mathrm{mg} \mathrm{FeSO}_{4} .7 \mathrm{H}_{2} \mathrm{O} ; 1.6 \mathrm{mg}$ $\mathrm{MnSO}_{4} \cdot 2 \mathrm{H}_{2} \mathrm{O} ; 1.4 \mathrm{mg} \mathrm{ZnSO} \cdot 7 \mathrm{H}_{2} \mathrm{O} ; 2 \mathrm{mg} \mathrm{CoCl} \cdot 6 \mathrm{H}_{2} \mathrm{O}$; and $10 \mathrm{~g}$ lactose. The initial $\mathrm{pH}$ was set as 5.5 . Thirty $\mathrm{ml}$ of the culture medium in $125 \mathrm{ml}$ flasks was inoculated with $0.9 \mathrm{ml}$ spore suspension $\left(1 \times 10^{6} \mathrm{spores} / \mathrm{ml}\right.$. $)$ to each flask and incubated at $28{ }^{\circ} \mathrm{C}$ in a shaker bath $(175 \mathrm{rpm})$ for 3 days. After recovery of the pellets using Whatman filter paper $\mathrm{N}^{\circ} 1$ (Whatman, Inc., Clifton, NJ), genomic DNA was extracted using the Wizard ${ }^{\circ}$ Genomic DNA Purification Kit following manufacture's instructions (Promega, Madison, WI, USA) and finally subjected to an additional purification step using the same purification kit. The quality and quantity of the purified DNA sample were evaluated by agarose gel electrophoresis and by using a NanoDrop1000 Spectrophotometer (Thermo Scientific, Wilmington, DE, USA).

\section{Genome sequencing and assembly}

The draft genome sequence of $A$. niger ATCC 10864 was generated at the University of Michigan Life Science Institute (Michigan, USA) using Illumina technology. Genomic DNA samples were sheared to approximately 400-450 bp fragment size, then Illumina-compatible sequencing libraries were prepared from those fragments on an Apollo 324 robotic workstation (WaferGen Biosystems), using the Kapa HTP Library Preparation Kit (KAPABiosystem) according to the manufacturer's protocols. Subsequent libraries were sequenced on an Illumina HiSeq $2000(100 * 2)$ platform with coverage of approximately 88.19X. Approximately, 1.59 million Illumina paired-end raw reads were generated, which was quality checked using FastQC 2.2 [20] and processed for adapters and low-quality $(<\mathrm{Q} 20)$ bases trimming. The trimmed reads were taken for further analysis.We have used in-house Perl script [21] for trimming adaptor and low-quality regions from the raw reads. Finally approx. 
Table 1 Classification and general features of Aspergillus niger strain ATCC 10864

\begin{tabular}{|c|c|c|c|}
\hline MIGS ID & Property & Term & Evidence code $^{a}$ \\
\hline & Current classification & Domain Fungi & TAS [37] \\
\hline & & Phylum Ascomycota & TAS [37] \\
\hline & & Class Eurotiomycetes & TAS [37] \\
\hline & & Order Eurotiales & TAS [37] \\
\hline & & Family Trichocomaceae & TAS [37] \\
\hline & & Genus Aspergillus (section Nigri) & TAS [37] \\
\hline & & Species Aspergillus niger & TAS [37] \\
\hline & & Strain ATCC 10864 & \\
\hline & Gram stain & N/A & \\
\hline & Cell shape & Septate and hyaline hyphae & TAS [38] \\
\hline & Motility & Non-motile & NAS \\
\hline & Sporulation & Carbon black ornamented spores from biseriate phialides & TAS [39] \\
\hline & Temperature range & $6^{\circ} \mathrm{C}-47^{\circ} \mathrm{C}$ & TAS [10] \\
\hline & Optimum temperature & $25-35^{\circ} \mathrm{C}$ & TAS [11] \\
\hline & $\mathrm{pH}$ range & $1.4-9.8$ & TAS [10] \\
\hline & Carbon source & Organic carbon source & TAS [40] \\
\hline MIGS-6 & Habitat & In soil, litter, compost and on decaying plant material & TAS [10] \\
\hline MIGS-6.3 & Salinity & $0-5 \%$ & TAS [41] \\
\hline MIGS-22 & Oxygen & Aerobic & TAS [10] \\
\hline MIGS-15 & Biotic relationship & Plant and animal & TAS [42] \\
\hline MIGS-14 & Pathogenicity & Mild/Opportunistic & TAS [10] \\
\hline MIGS-4 & Geographic location & Budapest, Hungary & TAS [9] \\
\hline MIGS-5 & Sample collection time & Unknown & \\
\hline MIGS-4.1 & Latitude & Unknown & \\
\hline MIGS-4.2 & Longitude & Unknown & \\
\hline MIGS-4.3 & Depth & Unknown & \\
\hline MIGS-4.4 & Altitude & Unknown & \\
\hline
\end{tabular}

${ }^{a}$ Evidence codes - TAS traceable author statement (i.e., a direct report exists in the literature), NAS non-traceable author statement

1.53 million reads were processed for assembly and annotation. De-novo assembly of Illumina paired-end data was performed using SPAdes assembler 3.1 [22] and assembled contigs were further scaffolded using SSPACE program [23]. Project information is shown in Table 2.

\section{Genome annotation}

The resulted scaffolds were predicted for proteins using Augustus 3.0.3 [24], and subsequently annotated using NCBI BLAST 2.2.29, e-value 0.00001 [25] with the proteins of the genera Aspergillus taken from Uniprot database (2016_1 release) [26]. Gene ontology (GO) terms of the predicted proteins in A. niger strain ATCC 10864 were assigned using Blast2GO tool version 4.0.7. Secondary metabolite (SM) clusters and pathway analyses were conducted by antiSMASH 3.0 [27] and KAAS (KEGG Automatic Annotation Server) [28] tools respectively. The $A$. niger ATCC 10864 proteins were subjected for CAZymes
(Carbohydrate-Active Enzymes) annotation using dbCAN (dbCAN HMMs 5.0) [29] servers, which are based on the CAZy database classification (2013 release) [30].

\section{Genome properties}

The assembly of the draft genome sequence consists of 310 scaffolds amounting to $36,172,237 \mathrm{bp}$, and the $\mathrm{G}+\mathrm{C}$ content is $49.50 \%$ (Table 3 ). It included a predicted 10,804 protein coding genes among which majority of genes (98.06\%) assigned a putative function. Additionally, 169 (1.56\%) RNA genes, 8430 (76.82\%) genes with Pfam domains, 994 (9.05\%) genes with signal peptides, and $2362(21.86 \%)$ genes with transmembrane helices have also identified in this study (Table 3). Among all the predicted genes, 7509 $(69.50 \%)$ were placed in 25 general COG functional gene categories. The distribution of the predicted genes, which 


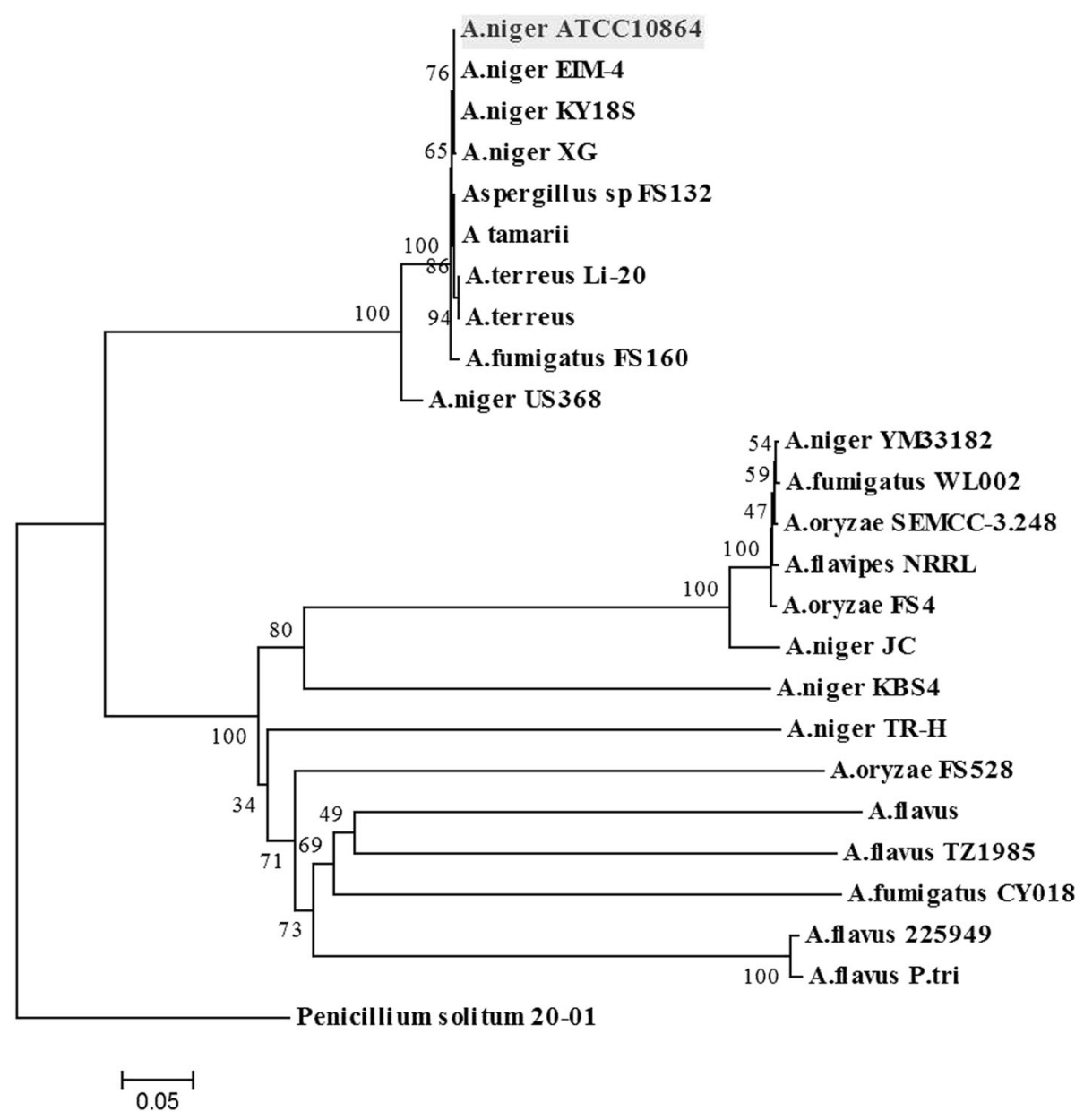

Fig. 2 Phylogenetic tree showing the close relationship of A. niger strain ATCC 10864 (grey block) with other A. niger strains based on aligned sequences of the $18 \mathrm{~S}$ rRNA gene. Multiple sequence alignment was performed using ClustalX program and the phylogeny was calculated using maximum likelihood method based on the Tamura-Nei model. The bootstrap value was inferred from 1000 replicates. Penicillium solitum is considered as the outgroup for this analysis. The whole analysis was carried out using MEGA5 package [43]

Table 2 Project Information

\begin{tabular}{|c|c|c|}
\hline MIGS ID & Property & Term \\
\hline MIGS-31 & Finishing quality & $\begin{array}{l}\text { High-quality draft (Full } \\
\text { genome representation) }\end{array}$ \\
\hline MIGS-28 & Libraries used & libraries of 400-450 bp \\
\hline MIGS-29 & Sequencing platforms & Illumina HiSeq $2000\left(100^{*} 2\right)$ \\
\hline MIGS31.2 & Fold coverage & $88.19 X$ \\
\hline MIGS-30 & Assemblers & SPAdes v 3.1 \\
\hline \multirow[t]{5}{*}{ MIGS-32 } & $\begin{array}{l}\text { Gene calling method } \\
\text { (Gene prediction tool) }\end{array}$ & Augustus 3.0.3 \\
\hline & Locus tag & Not indicated \\
\hline & $\begin{array}{l}\text { Genbank ID } \\
\text { GOLD ID }\end{array}$ & $\begin{array}{l}\text { MCQH00000000 } \\
\text { Gp0155299 }\end{array}$ \\
\hline & GenBank Date of Release & 29-AUG-2016 \\
\hline & Bioproject & PRJNA300350 \\
\hline \multirow[t]{2}{*}{ MIGS-13 } & Source material identifier & ATCC 10864 \\
\hline & Project relevance & Industrial \\
\hline
\end{tabular}

are annotated with COG functional categories, is presented in Table 4.

\section{Insights from the genome sequence}

The whole genome sequence analysis of $A$. niger ATCC 10864 revealed the presence of several genes actively involved in biofilm formation, carbohydrate metabolism, and secondary metabolite biosynthesis. Currently, studies on the molecular mechanism of biofilm formation in the genera Aspergillus are limited. A previous report noted that acid protease-encoding gene pepA, sporulation regulating transcription factor brlA, and the beta-1,3-exoglucanase gene exgA may have a probable role during biofilm formation in A. oryzae because those genes were found to be expressed only in solid-state fermentation (SSF) when compared with submerged fermentation (SF) [31]. ExgA might play a role in glucan utilization and a combination of poor nutrition and mycelial attachment to a hydrophobic solid surface appears to be an inducing factor for exgA 
Table 3 Genome statistics

\begin{tabular}{lrc}
\hline Attribute & \multicolumn{1}{c}{ Value } & \% of Total \\
\hline Genome size (bp) & $36,172,237$ & 100.0 \\
DNA coding (bp) & $17,676,693$ & 48.87 \\
DNA G + C (bp) & $17,905,257$ & 49.50 \\
DNA scaffolds & 310 & \\
Total genes & 10,973 & 100.0 \\
Protein coding genes & 10,804 & 98.45 \\
RNA genes & 169 & 1.56 \\
Pseudo genes & Unknown & \\
Genes in internal clusters & Unknown & \\
Genes with function prediction & 10,761 & 98.06 \\
GO annotated proteins) & & \\
Genes assigned to CoGs & 7509 & 69.50 \\
Genes with Pfam domains & 8430 & 76.82 \\
Genes with signal peptides & 994 & 9.05 \\
Genes with transmembrane helices & 2362 & 21.86 \\
CRISPR repeats & N/A & \\
\hline
\end{tabular}

expression [31]. Genes like NADH:flavin oxidoreductase, alcohol dehydrogenase, malate dehydrogenase [32], transcription activator complex GCN, secondary metabolism regulator LaeA and cytoplasmic membrane protein coding gene rodA [33] may also have a possible influence during biofilm formation in A. fumigatus. A significant number of primary metabolism genes involved in sulfur amino acid biosynthesis and regulated by GCN are upregulated in $C$. albicans biofilms which also leads to the production of Sadeno-sylmethionine (SAM), a precursor of polyamines. Activation of the genes for SAM biosynthesis might be related to the production of a quorum-sensing molecule associated with biofilm formation [33]. The rodA gene belonging to the hydrophobins family encodes a cysteine-containing polypeptide that is assembled into a regular array of rodlets on the surface of conidia to render the surface highly hydrophobic. RodA gene has been reported to be upregulated in A. fumigatus biofilms [32]. We have detected all the aforesaid genes in A. niger ATCC 10864, which may regulate the process of biofilm

Table 4 Number of genes associated with general COG functional categories

\begin{tabular}{|c|c|c|c|}
\hline Code & Value & $\%$ of total & Description \\
\hline J & 324 & 2.99 & Translation, ribosomal structure and biogenesis \\
\hline A & 29 & 0.20 & RNA processing and modification \\
\hline K & 337 & 3.11 & Transcription \\
\hline L & 362 & 3.35 & Replication, recombination and repair \\
\hline B & 42 & 0.30 & Chromatin structure and dynamics \\
\hline D & 80 & 0.70 & Cell cycle control, cell division, chromosome partitioning \\
\hline Y & 2 & 0.01 & Nuclear structure \\
\hline V & 70 & 0.60 & Defense mechanisms \\
\hline T & 236 & 2.18 & Signal transduction mechanisms \\
\hline M & 179 & 1.65 & Cell wall/membrane biogenesis \\
\hline N & 3 & 0.02 & Cell motility \\
\hline Z & 51 & 0.40 & Cytoskeleton \\
\hline W & 0 & 0 & Extracellular structures \\
\hline$U$ & 90 & 0.80 & Intracellular trafficking and secretion \\
\hline $\mathrm{O}$ & 311 & 2.87 & Posttranslational modification, protein turnover, chaperones \\
\hline C & 437 & 4.04 & Energy production and conversion \\
\hline G & 813 & 7.52 & Carbohydrate transport and metabolism \\
\hline E & 910 & 8.42 & Amino acid transport and metabolism \\
\hline $\mathrm{F}$ & 129 & 1.19 & Nucleotide transport and metabolism \\
\hline $\mathrm{H}$ & 250 & 2.31 & Coenzyme transport and metabolism \\
\hline 1 & 409 & 3.78 & Lipid transport and metabolism \\
\hline P & 616 & 5.70 & Inorganic ion transport and metabolism \\
\hline Q & 600 & 5.55 & Secondary metabolites biosynthesis, transport and catabolism \\
\hline $\mathrm{R}$ & 1772 & 16.40 & General function prediction only \\
\hline S & 195 & 1.80 & Function unknown \\
\hline- & 3295 & 30.49 & Not in COGs \\
\hline
\end{tabular}


formation. Gene Ontology (GO) terms for the annotated genes of $A$. niger ATCC 10864 were placed into three broad categories: biological process (BP), molecular function (MF), and cellular components (CC). A pie chart in the additional file represented the distribution pattern of some top level GO terms for the three categories (Additional file 1). In BP category the highest represented GO term was transmembrane transport (5.21\%) followed by carbohydrate metabolic processes (2.43\%) and transcription (1.7\%). In MF category the most abundant GO terms include zinc ion binding (9.93\%), ATP binding (7.53\%) and oxidoreductase activity (5.71\%). Integral component of the membrane (13.91\%), nucleus (13.41\%) and cytosol (5.96\%) were the most representative GO terms in CC category. A total of 709 putative CAZymes families which are actively involved in carbohydrate metabolism have been identified in this study (evalue less than $10^{-05}$ has only been considered) and they were categorized into six functional classes such as Glycoside Hydrolases $(\mathrm{GHs})=279$, Carbohydrate Esterases $($ CEs $)=134$, Glycosyltransferases $(\mathrm{GTs})=123$, Auxiliary Activities (AAs) $=107$, Polysaccharide lyases $(\mathrm{PLs})=13$, and Carbohydrate-Binding Modules $(\mathrm{CBMs})=53$. Other genes involved in cellulose metabolism (Endoglucanase A, Endo-beta-1,4-glucanase D), xylan metabolism (Beta-xylanase), pectin metabolism (Endopolygalacturonase) and galactose metabolism (Galactose-1phosphate uridylyltransferase, UDP-glucose 4-epimerase, Galactose oxidase) have also been identified.

Secondary metabolites (SMs) are small bioactive molecules which provide a competitive advantage to the fungi producing them in various ways. They may improve nutrient availability (e.g., in the form of chelating agents such as siderophores), protect it against environmental stresses (e.g., pigments against UV irradiation), enhance its competitive interactions for nutrients with other microorganisms in ecological niches, decrease the fitness of their hosts, e.g., plants, animals, or humans, and act as a metabolic defense mechanism [34]. The scaffold sequences of $A$. niger ATCC 10864 were analyzed for secondary metabolite gene clusters using antiSMASH and a total of 71 gene clusters were detected among which polyketide synthases (PKSs $=21)$ and nonribosomal peptides synthases $(\mathrm{NRPSs}=21$ ) were found to be most abundant. Secondary metabolite pathway annotation of A. niger ATCC 10864 was predicted by KAAS server using genus Aspergillus as reference and we have identified several genes that are mainly involved in caffeine metabolism (urate oxidase, xanthine dehydrogenase), indole diterpene alkaloid biosynthesis
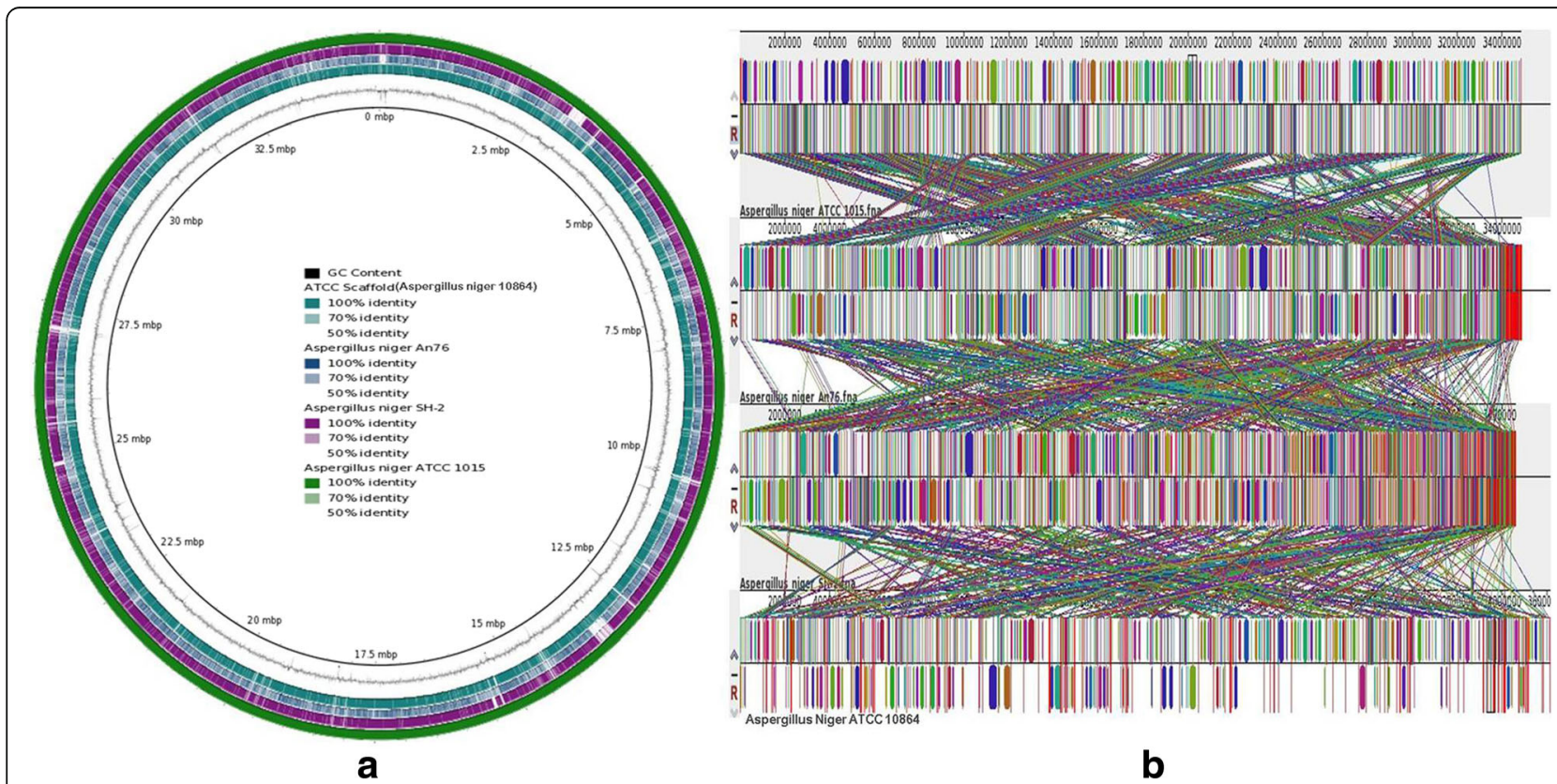

Fig. 3 Whole genome comparison analysis of A. niger ATCC 10864 with other reported A. niger strains. a Comparison of A. niger ATCC 10864, A. niger An76, and A. niger SH-2 strains against reference A. niger ATCC 1015 strain (using BRIG tool). The outermost dark green circle represents the reference genome of A. niger ATCC 1015; the next purple, blue and light green circle represent A. niger SH-2, A. niger An76, and A. niger ATCC 10864 strains respectively. The black line lying in between the A. niger ATCC 10864 and genome-scale symbolize the GC content. b Comparison of A. niger ATCC 10864, A. niger An76, and A. niger SH-2 strains against reference A. niger ATCC 1015 strain (using Mauve tool). Colored block outlines are known as Locally Collinear Blocks and are connected by corresponding coloured lines. LCBs represent the regions of similarity among the genomes that are homologous and have not undergone any rearrangement. Blocks lying above the center black horizontal line are in forward orientation while blocks below the center line indicate regions that align in the reverse complement (inverse) orientation. Regions outside blocks (white regions) show no homology among the input genomes 
(geranylgeranyl diphosphate transferase, FAD-dependent monooxygenase), aflatoxin biosynthesis (acetyl-CoA carboxylase, norsolorinic acid ketoreductase, versiconal hemiacetal acetate esterase), carbapenem biosynthesis (glutamate-5-semialdehyde dehydrogenase, glutamate 5-kinase), monobactam biosynthesis (aspartate kinase, aspartate-semialdehyde dehydrogenase, sulfate adenylyltransferase), penicillin and cephalosporin biosynthesis (isopenicillin-NN-acyltransferase).

A whole genome circular comparative map of $A$. niger 10,864 and other reported A. niger strains (ATCC 1015, An76, and SH-2) was generated using BRIG (Blast Ring Image Generator) v0.95 online tool [35]. All the scaffolds of $A$. niger ATCC 18064 were first stitched in a single scaffold and synteny map was constructed against the reference $A$. niger strain ATCC 1015. Each genome was represented by a different colour and the darkest areas in the circular genome displayed $100 \%$ sequence similarity with the reference genome, whereas the lightest (gray) areas showed $50 \%$ or less sequence similarity (Fig. 3a). From the BRIG analysis an overall of $85 \%$ similarity between the $A$. niger strain ATCC 10864 and A. niger strain ATCC 1015 is observed. Other two reference strains $A$. niger An76 and $A$. niger $\mathrm{SH}-2$ shows approximately $81-82 \%$ similarity against the $A$. niger ATCC 10864 strain (Fig. 3a). Multiple whole genome sequence alignment of the aforesaid strains was also performed using Mauve 2.3.1 [36] and A. niger 10,864 showed several non-homologous regions as compared to other $A$. niger strains (Fig. 3b).

\section{Conclusions}

This is the first high-quality draft genome sequence report of an A. niger strain which can form a fungal biofilm. We selected this ATCC 10864 strain for genome sequencing not only for its unique biofilm forming character but also due to the fact that when it forms biofilm it can produce a higher amount of lignocellulolytic enzymes than free-living cultures. We expect that the high-quality genome report of A. niger ATCC 10864 strain will contribute to new insights about the role of fungal biofilms for higher biotechnologically important enzymes production, which could be highly beneficial in future for industrial purposes.

\section{Additional file}

Additional file 1: Gene ontology pie chart of A. niger ATCC 10864. Distribution of Blast $2 \mathrm{GO}$ annotations of putative genes from $A$. niger ATCC 10864. The charts show annotations for Biological Process, Molecular Function and Cellular Components. (PDF 346 kb)

\section{Abbreviations}

CAZymes: Carbohydrate-Active Enzymes; COG: Cluster of Orthologous Groups; GRAS: Generally Recognized As Safe;" KAAS: KEGG Automatic
Annotation Server; MIGS: Minimum information about a genome sequence NAS: Non-traceable Author Statement; TAS: Traceable Author Statement

\section{Acknowledgements}

This work was supported by grants from Concejo Nacional de Ciencia y Tecnología of Peru [N 002-2013-CONCYTEC-FONDECYT and № 177-2015FONDECYT] and Programa Nacional de Innovación para la Competitividad y Productividad, Ministry of Production of Peru [N 176-FINCYT-IB-2013 and NN 177-FINCyT-IB-2013]. This work was also supported by the National Science Foundation under the $\mathrm{CCl}$ Center for Selective C - H Functionalization (CHE-1205646), and the Hans W. Vahlteich Professorship (D.H.S.). Authors acknowledge Genotypic Technology, Bengaluru, India for helping in the additional bioinformatic analysis.

\section{Authors' contribution}

$\mathrm{SP}$ executed the laboratory work, performed the analysis and wrote the first draft of the manuscript. YL carried out fungal cultures and genomic DNA extraction and purification. FY performed the sequencing process and the initial genome assembly and analysis. GKV, DHS, and MGC designed the study, helped to do the analysis and to write the manuscript. All authors read and approved the final manuscript.

\section{Competing interests}

The authors declare that they have no competing interests.

\section{Publisher's note}

Springer Nature remains neutral with regard to jurisdictional claims in published maps and institutional.

\section{Author details}

${ }^{1}$ Laboratorio de Micología y Biotecnología, Universidad Nacional Agraria La Molina, Av. La Molina s/n, 12 Lima, Peru. 'Life Sciences Institute, University of Michigan, 210 Washtenaw Avenue, Ann Arbor, Ml 48109-2216, USA.

Received: 9 November 2016 Accepted: 12 July 2017

Published online: 17 July 2017

References

1. de Vries RP, Visser J. Aspergillus enzymes involved in degradation of plant Cell Wall polysaccharides. Microbiol Mol Biol Rev. 2001;65:497-522. doi:10.1128/MMBR.65.4.497-522.2001

2. Ward OP, Qin WM, Dhanjoon J, Ye J, Singh A. Physiology and biotechnology of Aspergillus. Adv Appl Microbiol. 2006;58:1-75. doi:10.1016/S0065-2164(05)58001-8.

3. Villena G, Moreno P, Gutiérrez-Correa M. Cellulase production by fungal biofilms on polyester cloth. Agro-food-Industry Hi-Tech. 2001;12:32-5.

4. Villena GK, Gutiérrez-Correa M. Production of cellulase by Aspergillus niger biofilms developed on polyester cloth. Lett Appl Microbiol. 2006;43:262-8. doi:10.1111/j.1472-765X.2006.01960.X.

5. Gamarra NN, Villena GK, Gutiérrez-Correa M. Cellulase production by Aspergillus niger in biofilm, solid-state, and submerged fermentations. Appl Microbiol Biotechnol. 2010;87:545-51. doi:10.1007/s00253-010-2540-4.

6. Villena GK, Fujikawa T, Tsuyumu S, Gutiérrez-Correa M. Structural analysis of biofilms and pellets of Aspergillus niger by confocal laser scanning microscopy and cryo scanning electron microscopy. Bioresour Technol. 2010:101:1920-6. doi:10.1016/j.biortech.2009.10.036.

7. Villena GK, Gutiérrez-Correa M. Morphological patterns of Aspergillus niger biofilms and pellets related to lignocellulolytic enzyme productivities. Lett Appl Microbiol. 2007;45:231-7. doi:10.1111/j.1472-765X.2007.02183.x.

8. Villena GK, Fujikawa T, Tsuyumu S, Gutiérrez-Correa M. Differential gene expression of some lignocellulolytic enzymes in Aspergillus niger biofilms. Rev Peru Biol. 2009;15(2):097-102.

9. Faulds CB, Williamson G. Purification and characterization of a ferulic acid esterase (FAE-III) from Aspergillus niger: specificity for the phenolic moiety and binding to microcrystalline cellulose. Microbiology. 1994;140:779-87.

10. Schuster E, Dunn-Coleman N, Frisvad JC, Van Dijck PWM. On the safety of Aspergillus niger - a review. Appl Microbiol Biotechnol. 2002;49:426-35. doi:10.1007/s00253-002-1032-6.

11. Alborch L, Bragulat MR, Abarca ML, Cabañes FJ. Effect of water activity, temperature and incubation time on growth and ochratoxin a production by Aspergillus niger and Aspergillus carbonarius on maize kernels. Int J Food Microbiol. 2011;147:53-7. doi:10.1016/j.jffoodmicro.2011.03.005. 
12. Abarca LM, Accensi F, Cano J, Cabañez FJ. Taxonomy and significance of black Aspergilli. Antonie Van Leeuwenhoek. 2004;86:33-49. doi:10.1023/B: ANTO.0000024907.85688.05.

13. Pel HJ, de Winde JH, Archer DB, Dyer PS, Hofmann G, Schaap PJ, et al. Genome sequencing and analysis of the versatile cell factory Aspergillus niger CBS 513.88. Nat Biotechnol. 2007;25:221-31. doi:10.1038/nbt1282.

14. Andersen MR, Salazar MP, Schaap PJ, Van De Vondervoort PJI, Culley D, Thykaer J, et al. Comparative genomics of citric-acid-producing Aspergillus niger ATCC 1015 versus enzyme-producing CBS 513.88. Genome Res. 2011;21:885-97. doi:10.1101/gr.112169.110.

15. Yin C, Wang B, He P, Lin Y, Pan L. Genomic analysis of the aconidial and high-performance protein producer, industrially relevant Aspergillus niger SH2 strain. Gene. 2014;541:107-14. doi:10.1016/j.gene.2014.03.011.

16. Gutiérrez-Correa M, Villena GK. Surface adhesion fermentation: a new fermentation category. Rev Peru Biol. 2003;10(2):113-24.

17. Pagani I, Liolios K, Jansson J, Chen IMA, Smirnova T, Nosrat B, et al. The genomes OnLine database (GOLD) v.4: status of genomic and metagenomic projects and their associated metadata. Nucleic Acids Res. 2012;40:D571-9. doi:10.1093/nar/gkr1100.

18. Field D, Garrity G, Gray T, Morrison N, Selengut J, Sterk P, et al. The minimum information about a genome sequence (MIGS) specification. Nat Biotechnol. 2008;26:541-7. doi:10.1038/nbt1360.

19. Duff SJB. Use of surface-immobilized Trichoderma in batch and fed-batch fermentations. Biotechnol Bioeng. 1988;31:345-8.

20. Andrews S. FastQC: a quality control tool for high throughput sequence data. 2010. http://www.bioinformatics.babraham.ac.uk/projects/fastqc/

21. Annadurai RS, Neethiraj R, Jayakumar V, Damodaran AC, Rao SN, Katta MA, Gopinathan S, Sarma SP, Senthilkumar V, Niranjan V, Gopinath A. De novo transcriptome assembly (NGS) of Curcuma longa L. rhizome reveals novel transcripts related to anticancer and antimalarial terpenoids. PLoS One. 2013;8(2):e56217.

22. Bankevich A, Nurk S, Antipov D, Gurevich AA, Dvorkin M, Kulikov AS, et al SPAdes: a new genome assembly algorithm and its applications to singlecell sequencing. J Comput Biol. 2012;19:455-77. doi:10.1089/cmb.2012.0021.

23. Boetzer M, Henkel CV, Jansen HJ, Butler D, Pirovano W. Scaffolding pre-assembled contigs using SSPACE. Bioinformatics. 2011;27:578-9. doi:10.1093/bioinformatics/btq683.

24. Stanke M, Steinkamp R, Waack S, Morgenstern B. AUGUSTUS: a web server for gene finding in eukaryotes. Nucleic Acids Res. 2004;32(Suppl 2):W309-12. doi:10.1093/nar/gkh379.

25. Camacho C, Coulouris G, Avagyan V, Ma N, Papadopoulos J, Bealer K, Madden TL. BLAST+: architecture and applications. BMC Bioinformatics. 2009;10:421. doi:10.1186/1471-2105-10-421.

26. UniProt Consortium. Reorganizing the protein space at the universal protein resource (UniProt). Nucleic Acids Res. 2012;40:D71-5. doi:10.1093/nar/gkr981.

27. Weber T, Blin K, Duddela S, Krug D, Kim HU, Bruccoleri R, Lee SY, Fischbach MA, Müller R, Wohlleben W, Breitling R, Takano E, Medema MH. AntiSMASH 3.0 - a comprehensive resource for the genome mining of biosynthetic gene clusters. Nucleic Acids Res. 2015; doi:10.1093/nar/gkv437.

28. Moriya $Y$, Itoh M, Okuda S, Yoshizawa AC, Kanehisa M. KAAS: an automatic genome annotation and pathway reconstruction server. Nucleic Acids Res. 2007;35(Suppl 2):W182-5. doi:10.1093/nar/gkm321.

29. Yin Y, Mao X, Yang J, Chen X, Mao F, Xu Y. DbCAN: a web resource for automated carbohydrate-active enzyme annotation. Nucleic Acids Res. 2012;40:W445-51. doi:10.1093/nar/gks479.

30. Lombard V, Golaconda Ramulu H, Drula E, Coutinho PM, Henrissat B. The carbohydrate-active enzymes database (CAZy) in 2013. Nucleic Acids Res. 2014;42:D490-5. doi:10.1093/nar/gkt1178.

31. Gutiérrez-Correa M, Ludeña Y, Ramage G, Villena GK. Recent advances on filamentous fungal biofilms for industrial uses. Appl Biochem Biotechnol. 2012;167:1235-53. doi:10.1007/s12010-012-9555-5.

32. Muszkieta L, Beauvais A, Pahtz V, Gibbons JG, Leberre VA, Beau R, Shibuya K, Rokas A, Francois JM, Kniemeyer O, Brakhage AA, Latge JP. Investigation of Aspergillus fumigatus biofilm formation by various "omics" approaches. Front Microbiol. 2013;4:13. doi:10.3389/fmicb.2013.00013.

33. Fanning S, Mitchell AP. Fungal biofilms. PLoS Pathog. 2012;8(4):e1002585. doi:10.1371/journal.ppat.1002585.

34. Tudzynski B. Nitrogen regulation of fungal secondary metabolism in fungi. Front Microbiol. 2014;5:656. doi:10.3389/fmicb.2014.00656.
35. Alikhan N, Petty NK, Zakour NLB, Beatson SA. BLAST ring image generator (BRIG): simple prokaryote genome comparisons. BMC Genomics. 2011; 12:402. doi:10.1186/1471-2164-12-402.

36. Darling AC, Mau B, Blattner FR, Perna NT. Mauve: multiple alignment of conserved genomic sequence with rearrangements. Genome Res. 2004;14:1394-403. doi:10.1101/gr.2289704.

37. Klich MA. Identification of common Aspergillus species. Utrecht, The Netherlands; Centraalbureau voor Schimmelcultures.2002; ISBN 90-70351-46-3.

38. Tanaka K, Yanagita T. Electron microscopy on ultrathin sections of Aspergillus niger. II. Fine structure of conidia-bearing apparatus. J Gen Appl Microbiol. 1963;9:189-203. doi:10.2323/jgam.9.189.

39. Raper KB, Fennell DI. The genus Aspergillus. New York: Williams and Wilkins; 1965

40. Margaris NS, Mitrakos K, Markou S. Carbon sources for Aspergillus niger growth under different shaking programmes. Folia Microbiol. 1974;19:394-6. doi:10.1007/BF02872826.

41. Mert HH, Dizbay M. The effect of osmotic pressure and salinity of the medium on the growth and sporulation of Aspergillus niger and Paecilomyces lilacinum species. Mycopathologia. 1977;61:125-7. doi:10.1007/BF00443842.

42. Curtis RW, Stevenson WR, Tuite J. Malformin in Aspergillus niger-infected onion bulbs (Allium cepa). Appl Microbiol. 1974;28:362-5.

43. Tamura K, Peterson D, Peterson N, Stecher G, Nei M, Kumar S. MEGA5: molecular evolutionary genetics analysis using maximum likelihood, evolutionary distance, and maximum parsimony methods. Mol Biol Evol. 2011;28(10):2731-9. doi:10.1093/molbev/msr121

\section{Submit your next manuscript to BioMed Central and we will help you at every step:}

- We accept pre-submission inquiries

- Our selector tool helps you to find the most relevant journal

- We provide round the clock customer support

- Convenient online submission

- Thorough peer review

- Inclusion in PubMed and all major indexing services

- Maximum visibility for your research

Submit your manuscript at www.biomedcentral.com/submit
C Biomed Central 